\title{
EDIFICAÇÕES PÚBLICAS ADAPTADAS: UM ESTUDO DE CASO DA CIRCULAÇÃO HORIZONTAL
}

\author{
BARROS, Bruno (1); \\ FARIAS, Tárcio (2); \\ SILVA JÚNIOR, José Adilson (3). \\ (1) Universidade Federal de Pernambuco, Mestre \\ e-mail: barros bruno@hotmail.com \\ (2) Universidade Federal de Pernambuco, Bacharel \\ e-mail: tarciofcbranco@hotmail.com \\ (3) DeVry I UNIFAVIP, Mestre \\ e-mail: silvajunior.adilson@hotmail.com
}

\begin{abstract}
RESUMO
Apesar dos ambientes serem projetados para uma determinada utilização, paulatinamente podem haver modificações na finalidade para qual ele foi planejado originalmente, gerando a necessidade de adaptação para o novo uso. O presente artigo, através de uma análise antropométrica, identificou se a circulação interna da casa do estudante de uma universidade pública, atualmente adaptada para abrigar escritórios administrativos, está adequada ao seu novo uso. Foi utilizado o Método de Avaliação da Circulação Horizontal Interna dos Ambientes e os resultados possibilitaram observar a inadequação da edificação para o uso atual, além de apontar possíveis modificações que beneficiariam a funcionalidade da circulação horizontal.
\end{abstract}

Palavras chave: edificação adaptada; casa do estudante; análise antropométrica.

\begin{abstract}
Although they were originally planned, generating the need for adaptation to the new use. This article, through an anthropometric analysis, identifies an internal circulation of the student's home of a public university, nowadays adapted to house administrative offices, is willing to use it again. The Internal Horizontal Circulation Method of the Environments was used and the results allowed to observe an inadequacy of the building for the current use, besides pointing out possible modifications that benefit the functionality of the horizontal circulation.
\end{abstract}

Keywords: adapted building; student house; anthropometric analysis.

\section{INTRODUÇÃO}

A antropometria se relaciona com o estudo das medidas do corpo humano utilizando-se de comparações. É através dela que podem ser alcançados resultados satisfatórios no desenvolvimento de projetos em que o ser humano irá interagir com o ambiente e com o mobiliário contido nele, gerando assim, uma interface. Esses móveis influenciam no espaço 


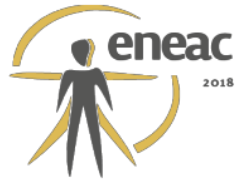

de trabalho em que o usuário exerce suas atividades, podendo ocasionar prejuízos na eficiência ou total comprometimento delas, caso estejam dimensionados inapropriadamente.

A circulação horizontal interna é a área resultante da subtração do espaço ocupado pelo mobiliário da área do ambiente interno. É através do cuidadoso processo projetual, considerando também o mobiliário, que se planeja o ambiente interno de maneira a atender as necessidades ao qual ele se destina, a fim de se obter espaços de trabalho realmente adequados para o ser humano.

Entretanto, ocasionalmente pode haver mudanças na finalidade do uso de algumas edificações ou ambientes. Dessa forma, é comum se deparar com locais que originalmente eram destinados ao uso residencial e passaram a ser utilizados para fins comerciais, muitas vezes devido à localização estratégica em relação a área urbana em que estão inseridos. Essas mudanças podem exigir várias adaptações no espaço e no mobiliário, dependendo do novo uso a que se destina.

Nesse contexto, a pesquisa teve como objetivo principal identificar, através de uma análise antropométrica, se a circulação interna do primeiro pavimento da edificação da casa do estudante de uma universidade pública federal, adaptada para edifício administrativo, está adequado ao novo uso. Por ter sido projetado para outra finalidade, partiu-se do pressuposto que a adaptação pode ter comprometido a qualidade da circulação interna do edifício.

Essa investigação classifica-se como estudo de caso e adotou o Método de Avaliação da Circulação Horizontal Interna dos Ambientes (MACHIA), na verificação da adequação do ambiente construído. Este método avalia os aspectos antropométricos identificados e os confronta por meio de simulações da circulação horizontal em uso, utilizando manequins antropométricos em plantas de layout dos ambientes.

\section{FUNDAMENTAÇÃO TEÓRICA}

\subsection{Personalização dos Lugares}

Ao se apropriar de um lugar, estabelecendo nele o seu habitar, o homem busca modificá-lo à medida que lhe é mais conveniente. Essas modificações podem envolver aspectos físicos da edificação, com mudanças em formas dos ambientes, aberturas, cobertura e revestimentos, bem como no mobiliário. É neste último, talvez, que a variedade de modificações seja mais evidente, provavelmente pela maior facilidade de alteração e também pela maior reversibilidade delas.

No momento em que o arquiteto define como será o apartamento, por exemplo, ele apenas definiu espacialmente os lugares que compõem a habitação. Ou seja, ele definiu a moradia e como seus diferentes espaços se relacionam, sem limitar totalmente como o usuário fará uso destes espaços. Lamparelli (2003) em suas reflexões afirma que nenhuma das soluções espaciais que adotarmos para uma moradia será totalmente adequada, uma vez que as necessidades, expectativas e aspirações dos moradores com relação a sua moradia manifestam-se com o ato de morar (LAMPARELLI, 2003 apud CAMARGO, 2010, p. 12-13).

\subsection{O Projeto de Arquitetura para Moradias Universitárias}

Todo projeto de arquitetura se baseia em informações pertinentes e esclarecedoras em relação ao que será projetado, facilitando a geração de soluções espaciais que atendam às necessidades dos usuários que farão uso da edificação. A edificação possui, em parte, a 


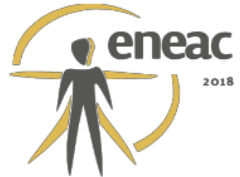

função de suporte para as diferentes atividades que envolvem o cotidiano desses usuários. Além disso, ela deverá transparecer sensações que possibilitem alguma identificação do usuário com o objeto edificado, agregando valor simbólico a ela.

Para Pride (1999), as principais características que diferenciam a moradia para estudantes são a disponibilidade de ambientes apropriados tanto para estudar quanto para morar, oferecendo oportunidades para o intercambio informal, acadêmico e social de conhecimento. Eles também devem preservar a privacidade e a tranquilidade, devido à estreita proximidade e compartilhamento de ambientes, muitas vezes com pessoas que os estudantes não tiverem opção de escolha. Essa diferença entre tipos de habitação pode ser um fator determinante para adaptação do indivíduo no novo ambiente, pois muitos estudantes não gostam de viver em torno de um ambiente institucional, apesar de valorizarem a sensação de fazerem parte de uma instituição com a qual se identificam (PRIDE, 1999).

Não por acaso a percepção institucional do espaço residencial é apontada [...] como um dos principais fatores de descontentamento com o ambiente residencial estudantil (SCOARIS, 2012, p.68), isto é, a falta de identificação do estudante para com o local onde irá residir é um fator desmotivador e incompatível com a realização da significativa atividade que é o habitar.

Especificamente no caso de moradias universitárias, Scoaris (2012) classifica essas informações em quatro eixos: 1| Caráter Institucional, onde se observa como a plástica da edificação transmite sensações percebidas pelos estudantes em relação a ela; 2| Potencial de Sociabilidade, que representa como a edificação pode contribuir para o aumento da socialização entre os seus usuários, gerando e desenvolvendo vínculos afetivos; 3| Suporte Funcional, onde são abordados quais equipamentos e mobiliários são essenciais para as atividades que envolvem a vida cotidiana do estudante no seu habitar; 4| Espaço Envolvente, que compreende como o edifício está inserido e qual seu envolvimento com o meio urbano que o cerca, de forma a contribuir ou prejudicar o seu desempenho.

\subsection{O Projeto de Arquitetura para Escritórios}

Edificações destinadas ao uso como escritório possuem aspectos específicos. Esta tipologia de edifício há anos é vítima de construtoras e empreiteiras que focam no maior lucro e conveniência possíveis, assim como o mínimo de risco do empreendimento. Como produto final obtêm-se uma edificação que satisfaz apenas necessidades simples de empresas que desenvolvem atividades repetitivas e pouco sujeitas a alterações (DEGW, 1999).

O autor supracitado questiona se tais edificações são capazes de atender novas necessidades do usuário, que possam surgir, sem que seja necessário realizar modificações substanciais no edifício (DEGW, 1999).

Kohn e Katz (2002) consideram que o processo de design de um edifício para escritórios deve ser desenvolvido por uma equipe multidisciplinar, devido a imposições comerciais e questões envolvidas que demandam cálculos e decisões que extrapolam a esfera de atuação do arquiteto.

Kohn e Katz (2002) afirmam que é crescente os requerimentos de algumas corporações para que sejam desenvolvidas soluções espaciais que possibilitem uma fácil conversão para locação de partes do empreendimento. Dessa forma, é provável que uma edificação para escritórios que atenda tal requisito possa ser mais adequada para adaptação de uso como moradia universitária do que o inverso.

Ainda segundo os autores existem dois tipos básicos de edificações destinadas ao uso como escritório e é exatamente na especificação do uso delas que se encontra a diferenciação. O primeiro tipo básico é o corporativo, que são edifícios para escritórios 


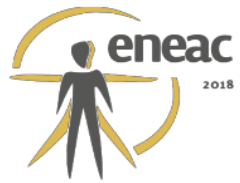

construídos para uso exclusivo de uma única empresa, que apresentará características espaciais que se adequam com maior especificidade ao desempenho de atividades ímpares de tal empresa. O segundo tipo básico é o especulativo, que são edifícios projetados para aluguel de mais de uma empresa e, logo, possuem características espaciais mais generalizadas, visto que não há como prever com exatidão no programa de necessidades quais atividades os inquilinos exercerão nos ambientes da edificação (KOHN; KATZ, 2002).

\subsection{Antropometria Aplicada ao Design de Interiores}

A antropometria se relaciona com o dimensionamento das formas e características físicas dos seres humanos e sua aplicação à esfera de projetos (PHEASANT, 1986 apud SEABRA, 2009). Portanto, para que um produto se adeque ao usuário, é necessário considerar os aspectos antropométricos dos usuários.

Jordan (1998) afirma que adequar o design de um produto ao usuário é indispensável para um projeto com usabilidade. O usuário pode ser apenas um indivíduo ou parte de uma população. Para ambos os casos é necessário levar em consideração os dados antropométricos no desenvolvimento do projeto. No entanto, a concepção de um projeto que atenda $100 \%$ das variações dimensionais de parte de uma população provavelmente teria um custo muito elevado de produção devido à sua complexidade (SEABRA, 2009).

Como solução para isto, Bridger (1995) apresenta dois conceitos básicos de aplicação de dados antropométricos chamados de Dimensões Mínimas e Dimensões Máximas. Ao se utilizar desses conceitos, o designer consegue atender maior parte dos usuários finais do produto de forma adequada.

Para aplicação da antropometria no design de interiores ou no projeto de arquitetura também é necessário conhecer quais dimensões físicas do ser humano devem ser levadas em consideração em diferentes tarefas a serem executadas no ambiente. É possível destacar a estatura, limites de movimento e alcances.

Para Panero e Zelnik (2002), a adequação do espaço acontece quando o usuário é capaz de se movimentar nele durante o uso, sem que haja colisão ou esbarramento em barreiras físicas, caracterizadas por equipamentos ou o mobiliário presente no ambiente e inclusive outras pessoas que estejam fazendo uso simultâneo do local. Os autores também categorizam os espaços em cinco diferentes zonas, a saber: zona da estação de trabalho; zona de execução da tarefa; zona de atividade/trabalho; zona da cadeira do visitante; zona de espaço livre (PANERO; ZELNIK, 2002).

As dimensões da zona de execução de tarefa, zona de atividade/trabalho e zona de cadeira de visitante são as mesmas, pois consideram o espaço mínimo necessário para circulação de um indivíduo, ou seja, 76,2cm (PANERO e ZELNIK, 2002). Tais medidas foram utilizadas na parte da avaliação do estudo de caso desta pesquisa.

\section{METODOLOGIA}

Para a condução da referente pesquisa, selecionou-se como método de procedimento o Método de Avaliação da Circulação Horizontal Interna de Ambientes - MACHIA (BARROS, 2009), que constitui uma maneira de verificar se o espaço disponível para o indivíduo se locomover no ambiente e utilizar o mobiliário presente nele é totalmente adequado, parcialmente adequado ou inadequado.

A aplicação do MACHIA, requer a utilização de duas ferramentas fundamentais: a planta de layout do ambiente projetado ou construído (em escala) e manequins antropométricos (também em escala). Logo, deve ser feita uma simulação do uso do ambiente através de 


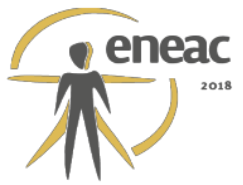

manequins antropométricos. Estes manequins são desenhos da figura humana em vista na planta de layout que possuem como base as medidas do ser humano adulto do sexo masculino sugeridas por Panero e Zelnik (2002).

A edificação deste estudo de caso, possui área construída de aproximadamente $1190,00 \mathrm{~m}^{2}$ e tem capacidade para 80 estudantes. A edificação é composta por dois blocos principais que se integram por um pátio interno no centro dela. Um dos blocos é destinado para estudantes do sexo feminino e o outro para estudantes do sexo masculino.

O programa foi distribuído de forma a priorizar a área íntima no $1^{\circ}$ piso onde se encontram 16 dos 20 dormitórios, copas e banheiros. Já o térreo abriga 04 dos dormitórios restantes, banheiros, áreas sociais, administrativas e de serviços, como pode ser visto na Figura 1, abaixo.

Figura 1: plantas baixas do térreo e $1^{\circ}$ piso da casa do estudante.
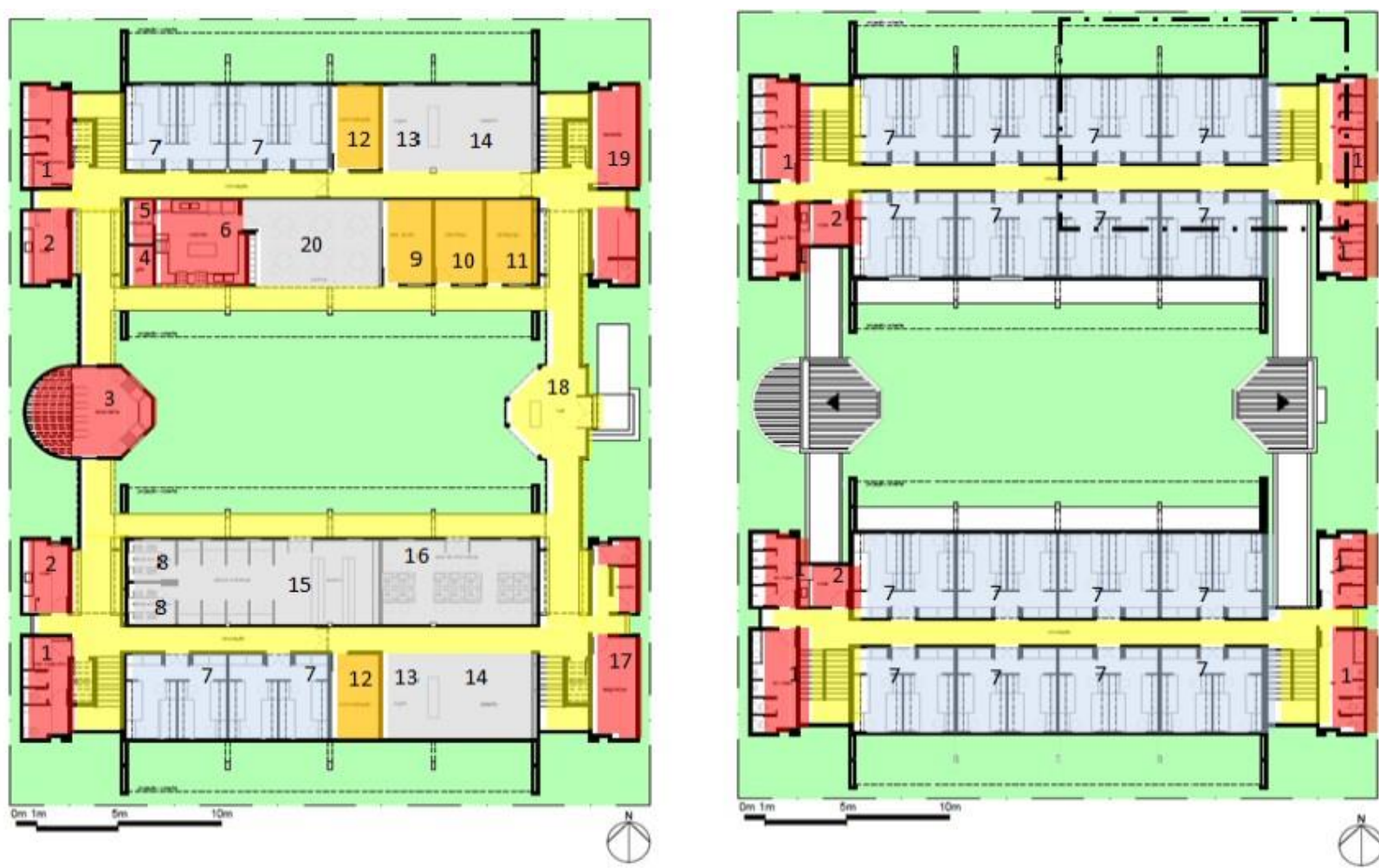

\section{ÁREA ÍNTIMA CIRCULAÇÃO SERVIÇOS ADMNISTRAÇÃO SOCIAL E ESTUDOS}

1. Banheiro| 2. Copa |3. Lavanderia|4. Gás |5. Despensa|6. Cozinha|7. Dormitório| 8. Sala de estudo em grupo | 9. Assistente social | 10. Psicólogo | 11. Pedagogo | 12. Administração | 13. Jogos | 14. Estar e TV | 15. Sala de leitura individual | 16. Sala de informática | 17. Vestiário dos funcionários | 18. Hall de entrada|19. Depósito|20. Refeitório

Fonte: Departamento de Planos e Projetos da Prefeitura da Cidade Universitária da Instituição de Ensino Superior. Editado pelos autores (2016).

As circulações que dão acesso direto aos quartos não possibilitam sua utilização como área de convívio e se conformam como corredores extensos e cerrados em ambos os lados, tornando necessária a utilização de iluminação artificial durante o dia e potencializando o aspecto institucional do espaço, como mostra a Figura 2, a seguir. 


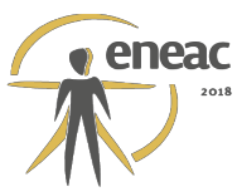

Figura 2: vista da circulação do $1^{\circ}$ piso da casa do estudante e seção da planta baixa do $1^{\circ}$ piso, respectivamente.

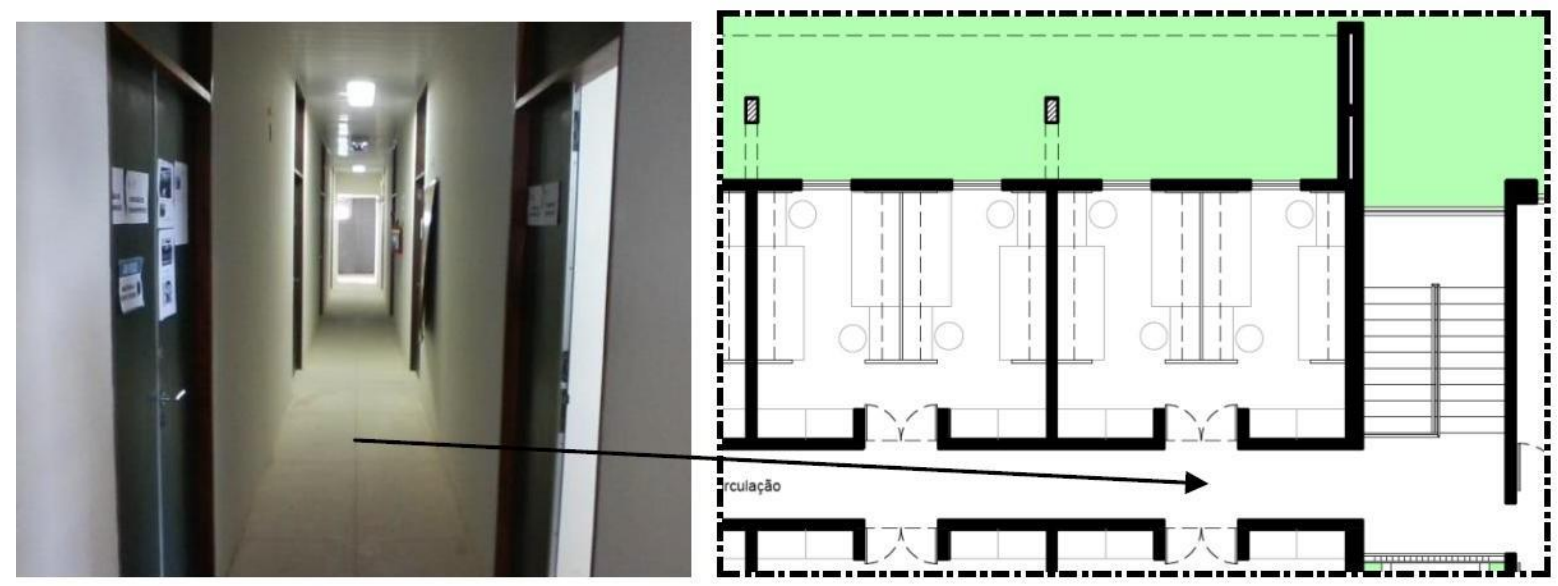

Fonte: Elaborado pelos autores para a pesquisa.

O mobiliário apresentado no projeto arquitetônico possui dimensionamento inferior ao sugerido no referencial teórico para as camas e mesas de estudo. A flexibilidade de disposição do mobiliário ficou bastante limitada e o conforto espacial do dormitório reduzido, apesar de conseguir abrigar um número maior de estudantes na área mínima de $10 \mathrm{~m}^{2}$ recomendada para apenas um, utilizando ainda a medida mínima de 2,40m.

\section{RESULTADOS}

A planta de layout (Figura 3) representando o atual uso e disposição do mobiliário do primeiro piso do edifício projetado para casa do estudante foi obtida através de levantamento in loco e as informações obtidas através dele foram inseridas na planta baixa disponibilizada pelo Departamento de Planos e Projetos da Prefeitura da Cidade Universitária da instituição de ensino seleciona para este estudo.

Foram identificadas pequenas variações no posicionamento dos móveis das salas destinadas ao uso das coordenações de curso. Dessa forma, os ambientes com layout e rota de circulação semelhantes serão avaliados em conjunto. O mobiliário de todas as salas é composto pelos mesmos itens: armário, birô, cadeira e gaveteiro.

Também foi identificado que, em salas que o uso se destinava a mais de três funcionários, a disposição dos móveis passava a ter maior variação, já que houve imensa distinção no posicionamento do mobiliário destes ambientes. Estas salas se destinam à outras funções e foram excluídas da avaliação deste trabalho por apresentarem acúmulo de atividades a serem desenvolvidas em um mesmo ambiente, tornando seu uso inadequado por este simples fato, independente da nova função destinada ao edifício. 


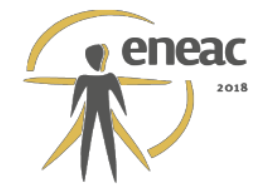

Figura 3: planta de layout do $1^{\circ}$ piso da casa do estudante.

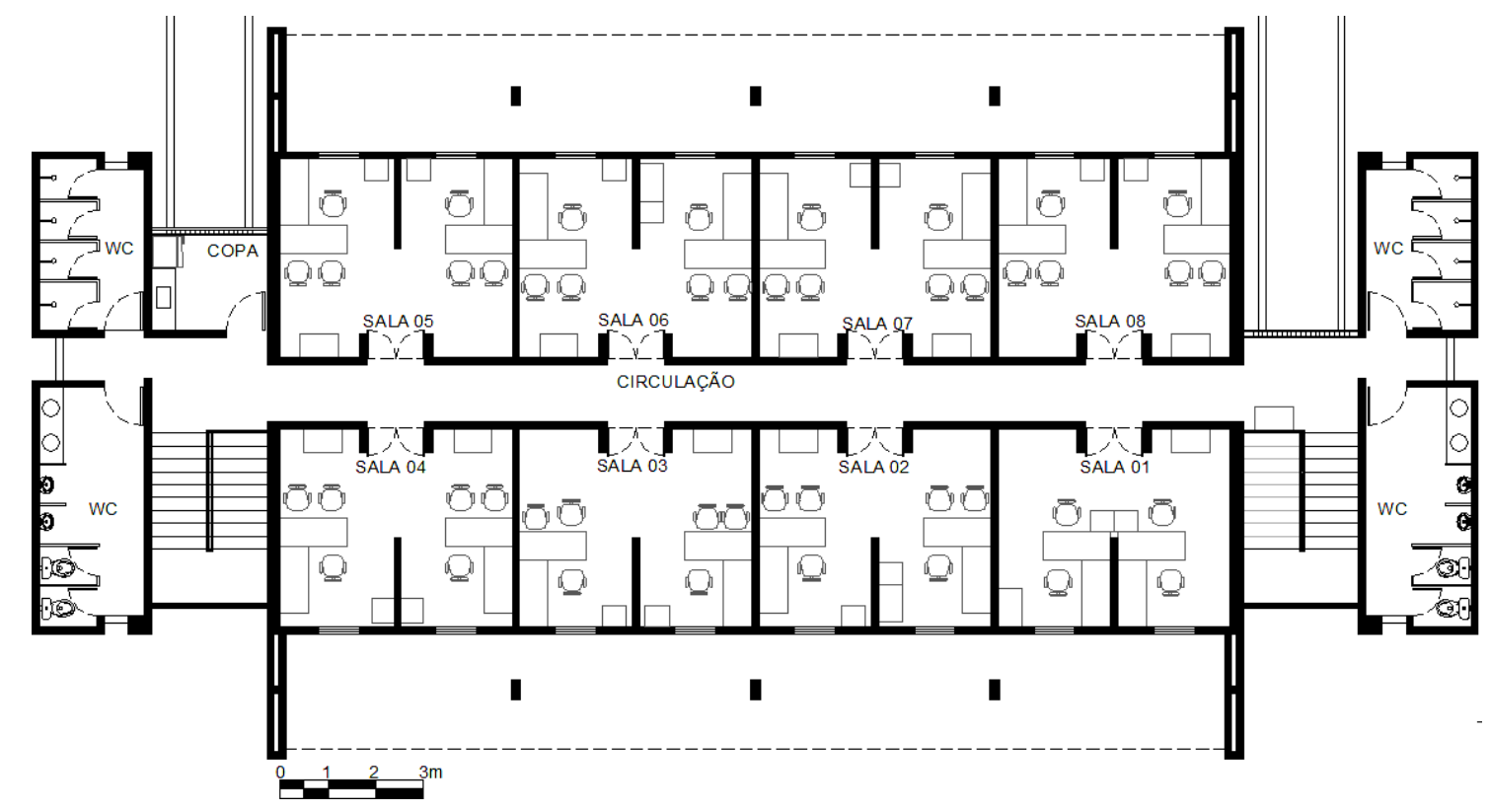

Fonte: Elaborado pelos autores para a pesquisa.

\subsection{Resultados Obtidos na Aplicação do MACHIA}

A inserção dos manequins auxiliares e rota de circulação foram feitas na planta de layout do primeiro piso da casa do estudante deste estudo de caso (Figura 4), enquanto inserção dos manequins de avaliação, foi realizada posteriormente, através do isolamento de partes da planta de layout, a fim de não comprometer a compreensão dos dados inserção dos manequins de avaliação, será feita através do isolamento de partes da planta de layout devido à limitação do tamanho das imagens.

Figura 4: aplicação dos manequins auxiliares e rota de circulação na planta de layout.

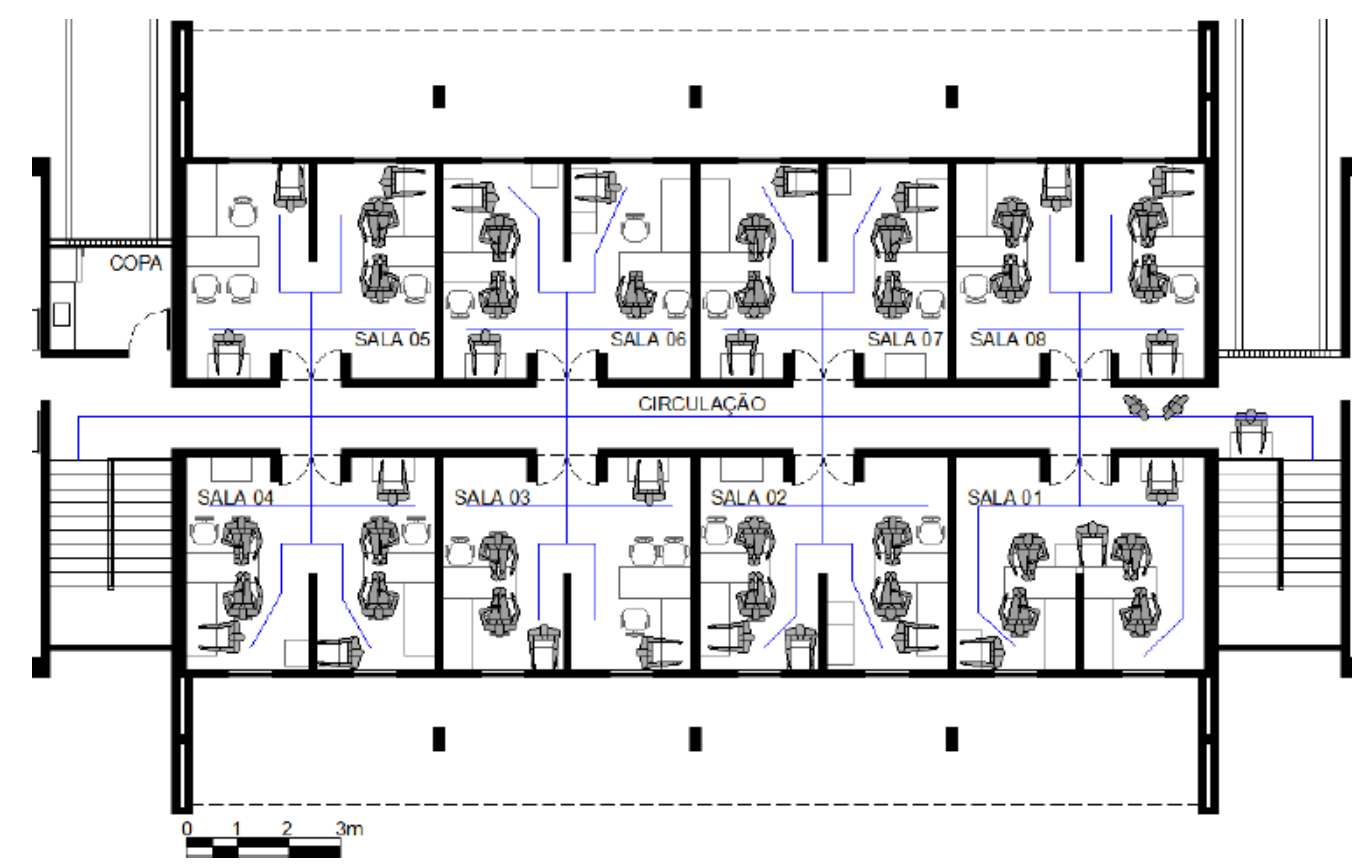

Fonte: Elaborado pelos autores para a pesquisa. 


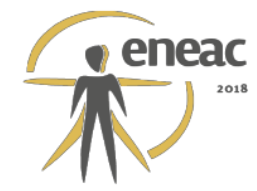

As salas 03, 05 e 08, apresentaram basicamente a mesma disposição dos móveis e rota de circulação. Nestas salas foram encontradas situações adequadas, parcialmente adequadas, que exigem atenção, e inadequadas (Figura 5). A circulação está adequada seguindo a rota que se inicia na porta de entrada do ambiente e segue até as janelas ou para o lado esquerdo da planta, onde não há armário. Porém, caso já haja uma pessoa utilizando o birô paralelo à parede ou o gaveteiro ao centro, a circulação para acesso a janela se apresenta como parcialmente adequada. A circulação inadequada deste ambiente pode ser vista na área entre o birô e o armário ao lado da porta de entrada. Caso haja alguma pessoa sendo atendida por um funcionário ou um funcionário esteja utilizando o armário, a circulação fica comprometida.

Figura 5: Aplicação do MACHIA na planta de layout das salas 03, 05 e 08.

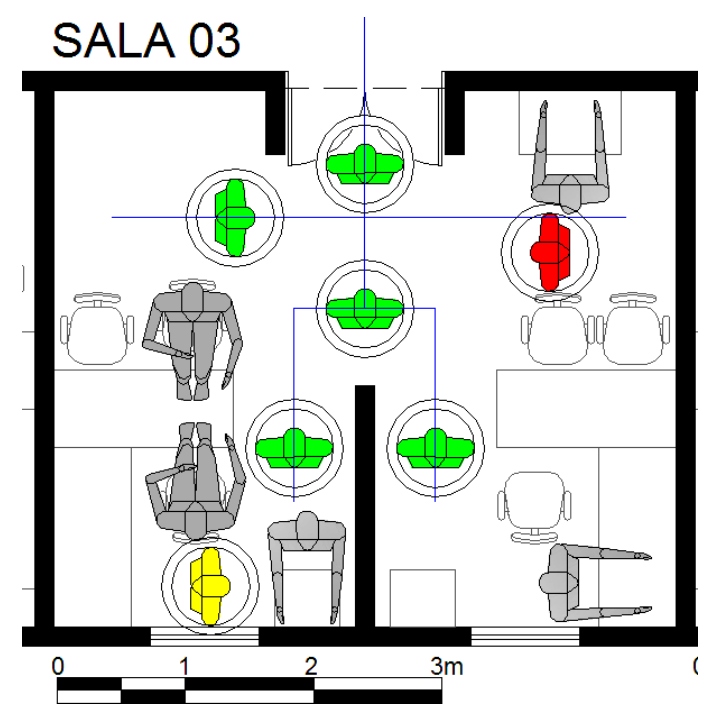

Fonte: Elaborado pelos autores para a pesquisa.

As salas 02 e 06 também apresentaram disposição do mobiliário e rota de circulação semelhantes. No entanto, para obtenção de mais resultados, foram geradas diferentes simulações de manequins auxiliares nestes ambientes, alternando entre o mobiliário sendo ou não utilizado. Observa-se que em ambos os casos (Figura 6) foram identificadas situações inadequadas quando parte do ambiente já está sendo utilizado por pelo menos 2 pessoas, como pode ser visto pelos manequins vermelhos próximos à porta de entrada da sala e na passagem entre o birô e o gaveteiro. Situações que exigem atenção foram encontradas no espaço próximo à janela, caso o birô paralelo à parede esteja sendo utilizado, e no acesso ao arquivo ao lado da porta, caso a cadeira esteja em uso. As situações adequadas se limitaram aos espaços em frente a porta de entrada, ao lado da porta de entrada, onde não há armário, e ao lado da parede de divisão no centro do ambiente, onde não há arquivo ou gaveteiro paralelo a ela. 


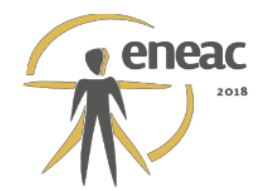

Figura 6: Aplicação do MACHIA na planta de layout das salas 02 e 06, respectivamente.

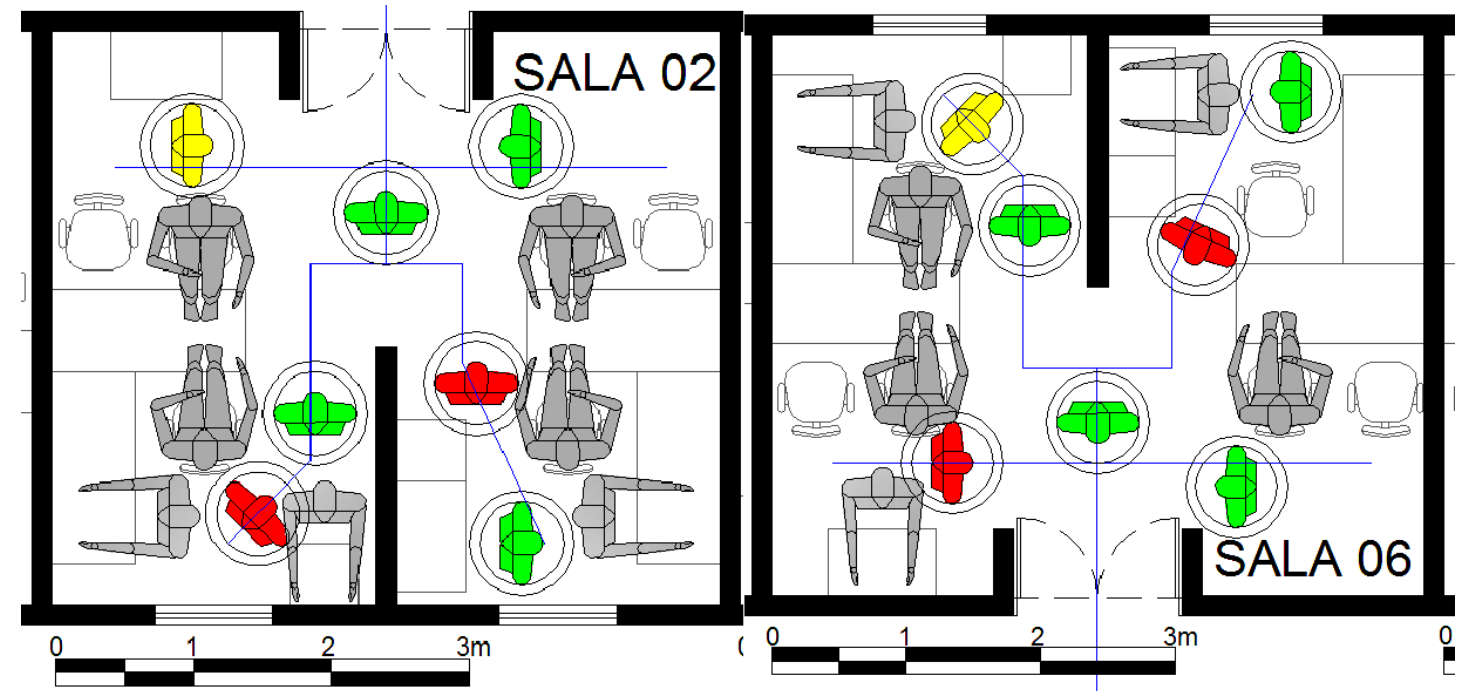

Fonte: Elaborado pelos autores para a pesquisa.

As salas 04 e 07 apresentaram layout praticamente idênticos e simétricos nos dois ambientes que compõem a sala. Da mesma forma que ocorreu nas salas anteriores, 0 espaço em frente a porta de entrada foi identificado como adequado para a circulação. Em adição, os espaços entre os birôs e a parede central que divide o ambiente também se encontraram adequados. As situações que exigiam atenção mais uma vez se voltavam para espaços em que havia parte do mobiliário sendo utilizado, como mostra os manequins em amarelo ao lado da porta de entrada e próximo a janela. As situações inadequadas, representadas pelos manequins em vermelho, foram os casos em que foi simulado o uso dos móveis por mais de uma pessoa em determinado espaço do ambiente (ver lado esquerdo da Figura 7, abaixo).

Figura 7: Aplicação do MACHIA na planta de layout das salas 04 e 07.

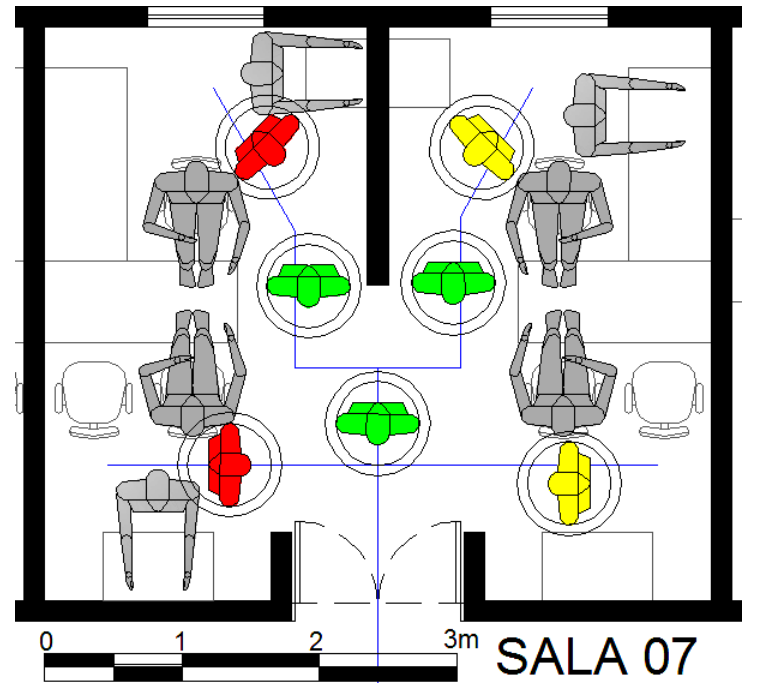

Fonte: Elaborado pelos autores para a pesquisa. 


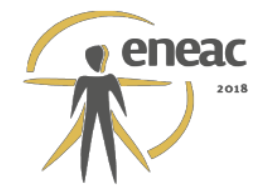

Na sala 01 (Figura 8) foi identificada 1 situação inadequada, o espaço para acesso a janela entre o birô e o armário do lado esquerdo da planta de layout. Apenas 2 situações de adequação parcial foram encontradas neste ambiente, o espaço entre o birô e o armário ao lado da porta de entrada e o espaço entre a cadeira e a janela, ambos do lado direito da planta de layout. O espaço imediatamente à frente da porta de entrada da sala e os espaços entre os birôs e as paredes foram identificados como adequados e estão destacados pelos manequins verdes.

Figura 8: Aplicação do MACHIA na planta de layout da sala 01.

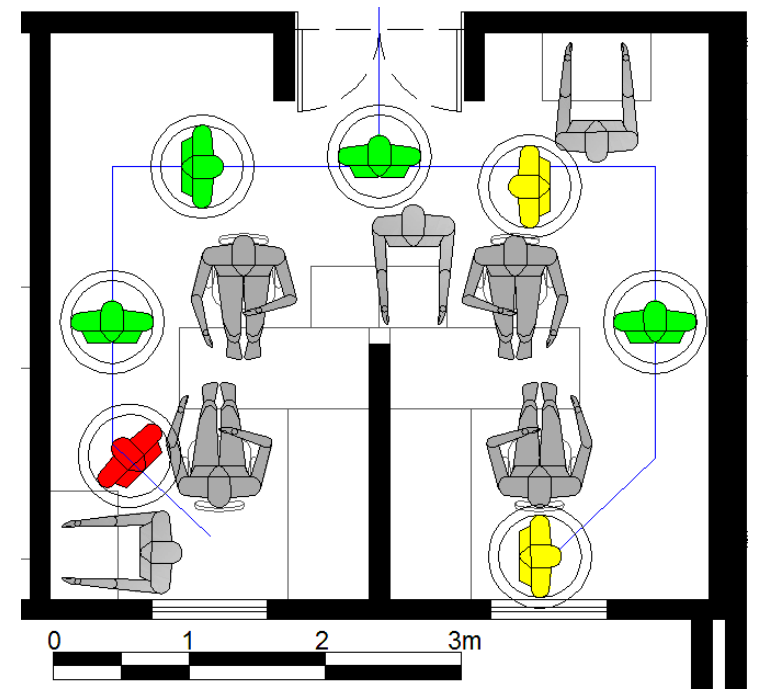

Fonte: Elaborado pelos autores para a pesquisa.

Em relação a circulação de acesso às salas do $1^{\circ}$ piso, praticamente não existe qualquer peça de mobiliário, exceto por uma máquina de impressão e fotocópias sobre um gaveteiro, localizada no início do corredor de acesso. Contudo, há vários painéis informativos expostos nas paredes ao longo de toda a circulação e, caso algum usuário pare para realizar a leitura, criará uma barreira física semelhante àquelas simuladas pelos manequins auxiliares. Desta forma, foi utilizado um manequim de avaliação na cor cinza, representando uma simulação deste tipo de uso, como mostra a Figura 9.

Figura 9: Vista da circulação de acesso as salas e aplicação do MACHIA na planta de layout.

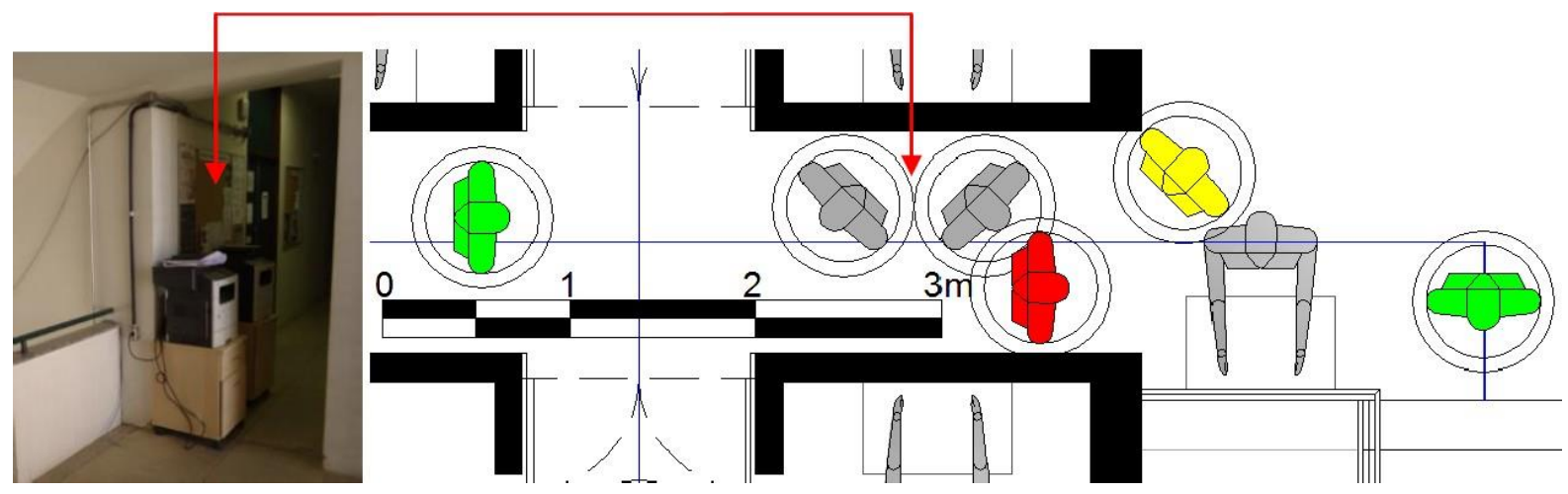

Fonte: Elaborado pelos autores para a pesquisa. 


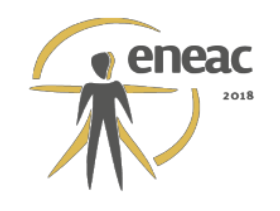

Apesar da ausência de peças de mobiliário ao longo da circulação, os painéis informativos contribuíram para geração de uma situação inadequada. Isto pode ser visto pelo manequim em vermelho acima, onde há uma simulação de duas pessoas conversando em frente ao painel exposto na parede (ver seta indicativa na Figura 9). Foi identificada também uma situação que exige atenção ocasionada pelo móvel que abriga a impressora e fotocopiadora. A relocação deste item para o lado oposto do ambiente poderia evitar este estreitamento da circulação. Contudo, a ausência de ponto elétrico impossibilita o reposicionamento deste móvel. O espaço imediatamente após a escada e após o painel informativo foram classificados como adequados para a circulação neste ambiente.

Ao analisar o ambiente destinado à copa, não foram identificadas inadequações referentes à circulação de pessoas. Isto pode ser explicado pelo fato de não haver mobiliário para realização de refeições no local, como mesa e cadeiras (Figura 10).

Figura 10: Aplicação do MACHIA na planta de layout da copa.

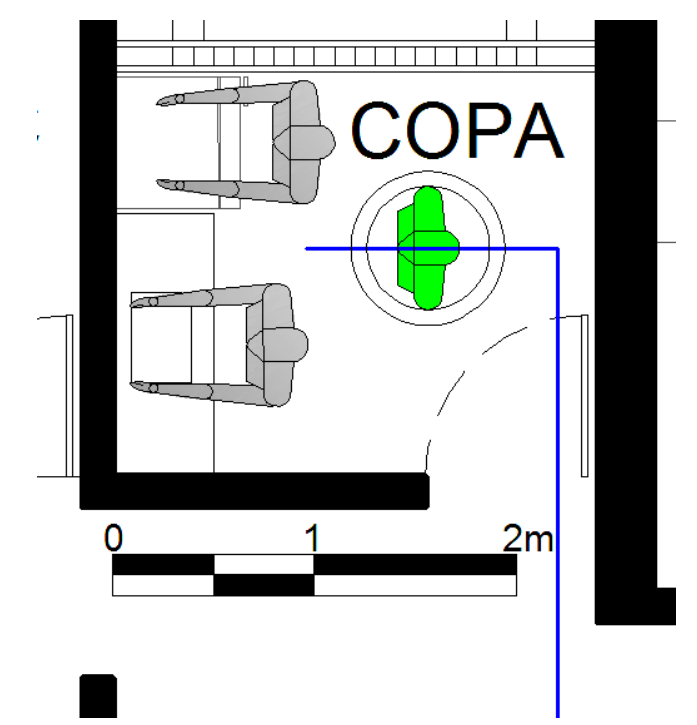

Fonte: Elaborado pelos autores para a pesquisa.

Considerando as dimensões reduzidas da copa, a inserção de outros itens de mobiliário certamente geraria situação de inadequação ou que exigiriam atenção quanto à circulação.

\section{CONCLUSÕES}

O presente estudo alcançou os objetivos esperados através da aplicação do MACHIA que se mostrou uma ferramenta eficiente para verificação da eficácia da adequação dos espaços analisados. O método, aqui aplicado, permite ainda visualizar possíveis problemas relacionados a espacialidade do ambiente que não são percebidos apenas com o layout do mobiliário, uma vez que simula cenários da utilização da edificação.

O estudo de campo se demonstrou realmente essencial aos objetivos específicos deste trabalho, tendo contribuído para coleta de dados da avaliação que permitiu concluir que o edifício se adequa ao novo uso, porém, com limitações. A eficiência espacial subutilizada pode ser destacada, pelo fato do prédio não ter sido projetado para o fim que se encontra atualmente. 


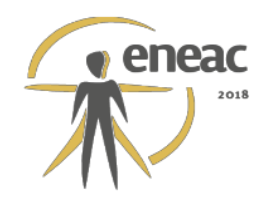

Intervenções na estrutura física da edificação certamente contribuiriam no alcance de maior eficiência do uso atual da edificação. Um dos pontos que são realmente preocupantes é a acessibilidade na edificação como um todo. Originalmente, o prédio foi projetado para ser acessível apenas no térreo, o que já é suficiente para contrariar o princípio de acessibilidade universal. Ainda assim, tal acessibilidade não contempla os banheiros nem os quartos, levando em consideração as exigências da NBR 9050 e o layout do mobiliário proposto no projeto original.

Os usuários e funcionários da edificação estão sujeitos à constrangimentos que tem origem no novo uso dela, como esbarrar em alguém ao se locomover nos corredores, ou ainda necessidade de locomoção para dar passagem a outros indivíduos dentro dos ambientes.

Por fim, acredita-se que utilizar o método na fase de projeto irá facilitar a realização de possíveis mudanças e adequações, reduzindo consideravelmente os custos e evitando que eventuais reformas sejam realizadas após a construção da edificação. Isto caracteriza o método como um teste de verificação que traz benefícios tanto econômicos como qualitativos ao projeto.

\section{REFERÊNCIAS BIBLIOGRÁFICAS}

BARROS, B. Avaliação antropométrica de espaços de circulação interna de ambientes: um método proposto. In CIPED 2009, Bauru - SP, 2009.

BRIDGER, R. S. Introduction to Ergonomics. Singapura: McGraw-Hill International Editions, 1995.

CAMARGO, É. N. Casa, doce lar: o habitar doméstico percebido e vivenciado. Érica Negreiros de Camargo - São Paulo: Annablume, 2010.

DEWG, O. In: ADLER, David (org.). Metric Handbook: Planning and design data. Oxford: Architectural Press, 1999.

JORDAN, P. An introduction to Usability. Londres: Taylor \& Francis, 1998.

KOHN, A. E.; KATZ, P. Building type basics for office buildings. Nova lorque: John Wiley \& Sons, 2002.

PANERO, J.; ZELNIK, M. O dimensionamento Humano para Espaços Interiores.

Barcelona, Espanha: Editorial Gustavo Gili, 2002.

PRIDE, L. Student Housing and House for Young People. In: ADLER, David (org.). Metric Handbook: Planning and design data. Oxford: Architectural Press, 1999.

SCOARIS, R. O. O projeto de arquitetura para moradias universitárias: contributos para verificação da qualidade espacial. Rafael de Oliveira Scoaris. São Paulo, 2012.

SEABRA, S. S. Análise antropométrica da circulação de espaços internos ambientados: um estudo de caso em três apartamentos residenciais da cidade de Caruaru- PE. Monografia. UFPE, 2009. 